\title{
Gobernanza territorial y gestión de espacios turísticos en contextos de fuerte presión inmobiliaria. Análisis de buenas prácticas locales en la costa de Cádiz (España) ${ }^{1}$
}

\author{
Alfonso Fernández Tabales ${ }^{2}$, Inmaculada Mercado Alonso ${ }^{3}$, \\ Arsenio Villar Lama ${ }^{4}$ y María Victoria Bascarán Estévez ${ }^{5}$
}

\begin{abstract}
RESUMEN
En la actualidad, el diagnóstico de los problemas que el desmesurado crecimiento urbano ha significado para los espacios turísticos españoles está muy avanzado. Una línea novedosa de investigación será el análisis de los escasos ejemplos en los que, a diferencia de la tendencia general, desde las instancias locales se ha optado por un modelo de desarrollo turístico ajeno al mero crecimiento inmobiliario. Los casos de buenas prácticas seleccionados en la Costa de Cádiz muestran que estos surgen vinculados a dinámicas de escala local, en las que la aplicación de nuevos enfoques de gobernanza territorial ha jugado un papel esencial. A partir de esta constatación se realiza una aproximación al debate teórico sobre la gobernanza territorial, un análisis crítico de los documentos de planificación incidentes, una valoración de los procesos de participación desarrollados y, finalmente, a través del tratamiento con SIG de ortofotografías de diferentes años, una cuantificación en términos superficiales de la realidad territorial resultante en el ámbito de estudio.
\end{abstract}

Palabras clave: Gobernanza territorial, Destinos turísticos litorales, Planificación y gestión de destinos, Ocupación del suelo, Buenas prácticas de gestión local.

\begin{abstract}
Diagnosis of the problems that excessive urban growth has meant for tourist destinations is Spain is currently well underway. A new line of research focuses on the analysis of the few examples where, bucking the general trend, local authorities have opted for a model of touristic development beyond mere real estate growth. Selected case studies of best practices along the Cadiz Coast show that their emergence is related to local dynamics, wherein the application of new approaches to territorial governance has played a core role. This finding is taken as the basis for an approach to the theoretical debate on territorial governance. In this work we provide a critical analysis of related planning documents, an assessment of the participation processes conducted, and finally, quantification of the territorial reality, based on surficial land use, in the study area based on GIS processing of orthophotos from various years.
\end{abstract}

Key words: Territorial governance, Coastal tourism destinations, Destination management planning, Land occupation, best local management practices.

\footnotetext{
1 Este artículo es resultado de los trabajos realizados en el Proyecto de Investigación "Gobernanza territorial y conformación espacial de destinos turísticos. Discursos, procesos y dialécticas en diferentes escenarios" (Ref CSO 2010-20284), financiado por el Ministerio de Ciencia e Innovación de España. Plan Nacional de I+D+i 2008-2011. Artículo recibido el 3 de diciembre de 2013, aceptado el 28 de agosto de 2014 y corregido el 8 de octubre de 2014.

2 Departamento de Geografía Física y Análisis Geográfico Regional, Universidad de Sevilla (España). E-mail: aftabales@us.es
}

\footnotetext{
Departamento de Geografía Física y Análisis Geográfico Regional, Universidad de Sevilla (España). E-mail: imercado@us.es

4 Departamento de Geografía Física y Análisis Geográfico Regional, Universidad de Sevilla (España). E-mail: arsenio@us.es

5 Departamento de Geografía Física y Análisis Geográfico Regional, Universidad de Sevilla (España). E-mail: vbascaran@us.es
} 
España representa un caso notable a nivel mundial dado el crecimiento del sector de la construcción y subsector de la vivienda desde los últimos años del siglo pasado hasta la eclosión de la actual crisis, con un incremento del parque inmobiliario cuya celeridad y extensión han popularizado expresiones tales como la de "tsunami urbanístico español" (García Bellido, 2005: 273). Ello la ha llevado a ocupar el primer puesto europeo en indicadores como los de incremento absoluto del número de viviendas construidas, número de viviendas por cada 1.000 habitantes, o stock de viviendas terminadas sin vender.

El posterior colapso de este modelo de crecimiento económico ha sido ya ampliamente analizado y diagnosticado, como la revisión bibliográfica mostrará a continuación, con especial atención a los espacios turísticos litorales, al ser estos ámbitos donde la oleada urbanizadora y constructiva alcanzó la máxima expresión. Es este el punto del que parte el presente artículo, al orientarse a analizar no tanto la generalidad de casos negativos ya conocidos, en los que se constata la desmesurada expansión de la urbanización y la incapacidad de los instrumentos tradicionales de planificación para racionalizar el fenómeno, sino aquellos otros ejemplos, muy escasos, en los que se han generado dinámicas locales vinculadas a experiencias de gobernanza, dirigidas a proponer modelos territoriales más sostenibles a largo plazo para los espacios turísticos litorales.

Por tanto, la pregunta clave de investigación que se plantea en este artículo será: ¿Ante la frustración por la incapacidad de los instrumentos tradicionales de planificación territorial, es posible articular estrategias locales de gestión territorial, con un enfoque de gobernanza, para limitar las oleadas urbanizadoras en contextos de elevada presión inmobiliaria?

$Y$ en coherencia con esta pregunta, los objetivos buscados serán: contribuir al debate teórico de la gobernanza territorial como enfoque para el tratamiento de los espacios turísticos litorales; presentar los casos de los municipios de Conil de la Frontera y Tarifa, ambos en la costa de Cádiz (España), como ejemplos significativos al respecto, dada la muy infrecuente adopción de estrategias limitadoras del crecimiento urbano; analizar, diagnosticar y valorar los procesos de participación que han generado dichas estrategias; y establecer, a través del tratamiento con SIG de ortofotografías de diferentes años, una cuantificación en términos superficiales de la realidad territorial resultante en el ámbito de estudio.

La metodología se ha basado, tras la previa revisión bibliográfica de la literatura científica sobre la materia que ha permitido elaborar el marco teórico, en un análisis crítico de los documentos de planificación, de diverso tipo, que han incidido sobre la definición del modelo territorial-turístico implantado en los ámbitos de estudio; poniendo especial énfasis en el grado de participación social en la elaboración de los mismos y en el nivel de concreción de sus propuestas de carácter territorial. Para la evaluación del incremento de la superficie ocupada por la urbanización en los ámbitos analizados, se ha procedido a aplicar una metodología basada en la utilización de ortofotografías de diferentes años y su tratamiento mediante SIG, de forma que puede apreciarse y cuantificarse la superficie de suelo cubierto por la urbanización y su evolución diacrónica. En concreto, se han utilizado las series de ortofotografías aéreas de Andalucía correspondientes a los años 1998, 2002, 2006, 2008 y 2010 (Consejería de Obras Públicas y Transportes, Junta de Andalucía), cuya elevada resolución espacial (píxeles de $1 \times 1$ metro) permite el necesario tratamiento de detalle. La utilización de esta fuente tiene asimismo como ventaja la posibilidad de comparación con otros trabajos previos realizados sobre el litoral andaluz (Villar, 2012), lo cual permitirá contrastar la singularidad del caso de Conil en su contexto territorial y cronológico.

Por último, se ha procedido a superponer la información territorial extraída de las ortofotografías con el plano de clasificación de suelo del planeamiento urbanístico vigente en cada momento de la serie temporal, para así apreciar la expansión de la construcción en suelo no urbanizable; si bien no es esta una cuestión en la que se vaya a profundizar dada la extensión de este artículo. 


\section{Revisión teórica. El enfoque de la gobernanza territorial aplicado a los destinos turísticos}

Este artículo se enmarca dentro de las contribuciones que tratan de analizar las repercusiones espaciales y sectorial-turísticas de las nuevas lógicas de funcionamiento del sistema económico global en su relación con los territorios (Britton, 1991; loannides \& Debbage, 1998; Conrady \& Buch, 2007), en este caso a partir de los efectos de la globalización de los mercados inmobiliarios en la redefinición de los espacios de producción turístico-residencial en las regiones periféricas mediterráneas (Branwell, 2004), y más concretamente en el caso de España, donde dicha redefinición, plasmada en la acelerada urbanización de espacios litorales para la implantación de actividades turístico-residenciales, ha alcanzado su máxima expresión (Vera y Rodríguez, 2010; Capel, 2010; Naredo y Montiel, 2011; Hof \& Blázquez-Salom, 2013).

Dichas lógicas están estrechamente vinculadas a aspectos tales como las fluctuaciones a corto-medio plazo de las políticas crediticias y su relación con las denominadas "burbujas inmobiliarias" (Stevenson \& Young, 2006; Hamnett, 2009), la movilidad internacional del capital en su relación con la urbanización (Palan et al., 2010; Capel, 2010b), la globalización de las formas de ocio y de las estructuras espaciales ligadas a las mismas (Dredge, 2001; Murray et al., 2005; Agarwal, 2005; Murray, 2012), o la internacionalización de los mercados inmobiliarios asociada a las migraciones internacionales de jubilados o "migraciones de amenidad" (en inglés amenity-led migrants) (Williams y Hall (2000); Hays \& Longino, 2002; Walters, 2002; Patterson, 2006; Warnes \& Williams, 2006; Janoschka, 2013). Todo ello forma parte de procesos de largo recorrido en el seno de los cuales se genera la conformación de unos nuevos territorios litorales, caracterizados por la yuxtaposición y fusión de usos residenciales y turísticos, conformación espacial esta, además, que aparece subordinada a las citadas lógicas de acumulación de capital a corto plazo, en detrimento de un diseño territorial a medio-largo plazo con mayor sostenibilidad ambiental, social e incluso económica (Faulkner et al., 2001; Équipe MIT, 2011). Es en este contexto en el que se enmarcan los debates acerca de los modos de gestión pública más adecuados para afrontar los nuevos escenarios, debates en los que el concepto y la práctica de la gobernanza adquieren un papel cada vez más relevante.

El concepto de gobernanza como nuevo enfoque para afrontar la gestión de los asuntos públicos viene siendo uno de los más utilizados por las ciencias sociales en las últimas dos décadas (Pierre, 1999 y 2000; Paquet, 2009; Lipietz \& Pieterse, 2010). Si bien es un término sobre el que existe cierta imprecisión, en general se viene aceptando que la gobernanza sería "un nuevo estilo de gobierno, distinto del modelo de control jerárquico y caracterizado por un mayor grado de cooperación y por la interacción entre el Estado y los actores no estatales al interior de redes decisionales mixtas entre lo público y lo privado" (Mayntz, 2000). Así pues, según esta visión, no se trataría tanto de cambiar el modelo normativo-institucional, sino de adaptar sus estructuras y procesos a las nuevas condiciones, de manera que los productos del sistema político estén también más adaptados a los nuevos requerimientos sociales (Comisión Europea, 2001; Graham et al., 2003; Farinós, 2007; Henderson, 2010). Más recientemente se ha acuñado el concepto de gobernanza territorial o "Gèo-gouvernance" (Masson-Vincent, 2008; Dubus et al., 2010; Masson-Vincent et al., 2012) para designar su aplicación al ámbito territorial, tanto en lo relativo a la planificación territorial a diferentes escalas como a las políticas con incidencia territorial (Romero y Farinós, 2006).

A este respecto, se entiende por gobernanza territorial (Farinós, 2008)

"una práctica/proceso de organización de las múltiples relaciones que caracterizan las interacciones entre actores e intereses diversos presentes en el territorio (...) en este sentido, se interpreta como la emergencia y puesta en práctica de formas de planificación y gestión de las dinámicas territoriales innovadoras y compartidas (caracterizadas por la relación, negociación y formación de consensos), respaldadas por multiplicidad de actores que comparten 
unos objetivos y conocen y asumen cuál debe ser su papel en su consecución".

Estas visiones nacen ante la evidencia de las limitaciones de modelos de planificación y gestión anteriores, cuya aplicación práctica ha mostrado unos resultados a menudo alejados de los ambiciosos objetivos fijados, dada la distancia y difícil coordinación entre las diferentes escalas administrativas (estatal, regional, local) y de estas con los agentes económico-sociales y población en general. Ello se manifiesta de forma especialmente nítida en el tratamiento de los problemas territoriales en los que, dada la diversidad de políticas incidentes a diferentes escalas que acaban afectando a las dinámicas espaciales, así como a la diversidad de agentes privados interactuando sobre la realidad del territorio, se hace patente la necesidad de buscar unos consensos básicos u objetivos comunes sobre el modelo territorial deseable y unas prácticas de gestión verdaderamente participativas y coordinadas para llegar al mismo. (Swyngedouw, 2005; Sorensen \& Torfing, 2009; Pascual y Godás, 2010; Romero y Farinós, 2011).

En este contexto teórico, este artículo se enmarca en una nueva visión, como es la aplicación de estos principios a unos espacios caracterizados, y a menudo conformados, por su orientación hacia las actividades de turismo y ocio. Dichos espacios, entendidos como destinos turísticos, presentan una serie de rasgos singulares que los dotan de especial interés en relación al marco de ideas citado:

- Su extremada complejidad, tanto en lo morfológico como en lo funcional, al coexistir sobre el mismo territorio usos turísticos con usos productivos preexistentes o de conservación de la naturaleza, población residente con no residente, redes sociales tradicionales con otras generadas por la actividad turística, etc. (Équipe MIT, 2004; Antón y González, 2007).

- Su dinamismo, impulsado por la capacidad del sector de generación de rentas y empleos. De hecho, en el caso español en la pasada década, el turismo, asociado a la construcción, ha sido uno de los factores fundamentales de la rápida transformación experimentada por el territorio, en especial en las zonas litorales (Navarro, 2003; OSE, 2006; Rullán, 2011).

- La creciente importancia de la calidad territorial en sentido amplio (medio ambiente, paisaje, infraestructuras, equipamientos, servicios, etc.) como factor de competitividad de los destinos. Calidad territorial que, dada la variedad de sus componentes, dependerá de una multiplicidad de actuaciones practicadas por distintos agentes públicos y privados a diferentes escalas.

- El progresivo y singular impacto en estos espacios de la globalización o internacionalización de los procesos, reflejado en fenómenos tales como: la intensificación y aceleración de flujos de todo tipo que tienen a estas áreas como destinos (de personas, capital, tecnologías, modos de vida, etc.); la aparición de procesos de macroconcentración empresarial de los agentes intervinientes en la industria turística, que adquieren escala continental o incluso mundial, obligando a una difícil redefinición en sus funciones y operativas a los actores locales en destino; o la globalización del mercado inmobiliario, determinante como factor explicativo de las transformaciones territoriales experimentadas por los espacios turísticos litorales y rurales españoles en la última década (Rullán, 2012; Fernández y Cruz, 2013).

- La escasa y débil tradición de planificación integral de los destinos turísticos entendidos como tales, más allá de conjuntos de medidas de recualificación sectorial (Antón, 2004; Vera et al., 2011; Vera y Rodríguez, 2012). Ello ofrece un campo relativamente novedoso para la investigación y abierto a la aplicación de nuevos enfoques.

Todos estos rasgos refuerzan la necesidad, ampliamente compartida en el debate científico de los últimos años (Shaw \& Williams, 2004; López et al., 2005; Vives, 2011; Murray, 2012) de buscar nuevos enfoques de planificación y gestión de los destinos que garanticen la coordinación interadministrativa y la participación de los agentes socioeconómicos en el logro de objetivos comunes; acentuada en los tiempos más recientes por la evidencia 
de los impactos experimentados en la calidad territorial de los espacios turísticos más representativos, como son los de litoral.

Estos impactos han evidenciado las carencias políticas y técnicas de los modelos de planificación y gestión aplicados hasta el momento, detectándose una cierta frustración ante la escasez de resultados obtenidos frente al volumen de esfuerzos institucionales y científicos desarrollados desde los años ochenta en esta materia, en especial al constatar el desmesurado crecimiento inmobiliario y el resurgimiento del residencialismo en las áreas turísticas, cuyas negativas consecuencias a medio-largo plazo ya están nítidamente diagnosticadas desde la década de los setenta del siglo pasado (Vera et al., 2011); y que resultan especialmente preocupantes al haberse plasmado en territorios que, por su gran potencialidad de recursos, exigían un tratamiento orientado a fórmulas de mayor rentabilización turística a largo plazo, basadas en una oferta de servicios turísticos avanzados. Fórmulas, por otra parte, que han constituido el eje argumental del discurso político-institucional dirigido a estas áreas, cuyo distanciamiento de la realidad de los procesos socioterritoriales se ha hecho evidente en los últimos años.

Ante este escenario se consolida el diagnóstico de que la clave del problema reside en la incapacidad de prever, controlar o siquiera canalizar adecuadamente las dinámicas socioeconómicas que se desarrollan en los territorios concretos. Y que estas dinámicas son resultado de la actuación de redes formales o informales de agentes y actores: promotoras inmobiliarias, empresas turísticas, instituciones públicas locales, entidades financieras, sociedad civil articulada, propietarios del suelo, instituciones autonómicas y estatales (con competencias en materia turística, territorial, medioambiental, infraestructural, etc.), demanda turística, medios de comunicación.

Como consecuencia de todo ello, se abre paso tanto en los ámbitos político-técnicos como científicos la conciencia de que, sin abandonar los instrumentos tradicionales de planificación territorial (urbanismo y ordenación del territorio) y turística, se hace necesario reforzar estos y hacerlos más eficaces con actuaciones vinculadas al enfoque de la gobernanza territorial, centrado en la actuación sobre las citadas dinámicas sociales existentes en los destinos, y más específicamente en la gestión de los conflictos que inevitablemente surgen en el desarrollo de los mismos (Hall, 2004), dinámicas que finalmente encuentran su plasmación física en el territorio resultante.

A esta necesidad se une una oportunidad, como es la posibilidad de usar la potencialidad que encierra el turismo, y sus beneficios económicos y sociales, como un catalizador que estimule procesos socioculturales encaminados a lograr una mejor realidad territorial en los destinos. Dicha potencialidad se sustenta en los actuales requerimientos de competitividad que experimentan estos, en tanto que espacios cuya orientación al ocio y al disfrute del tiempo libre les hace especialmente sensibles a las exigencias de calidad territorial de los segmentos de demanda más cualificados y rentables (Vera y Rodríguez, 2012), incluyendo en dicha calidad con destacado y creciente vigor los aspectos paisajísticos (Exceltur, 2005). Estas exigencias desde el lado de la demanda (ya sea por cortos periodos como turistas o por largos en el caso de nuevos residentes extranjeros), pueden ser el factor desencadenante que impulse la creación de consensos sobre el modelo territorial y turístico que genere mayores beneficios a largo plazo al conjunto de la población local, modelo que necesariamente tendrá la calidad territorial en sentido amplio como uno de sus componentes esenciales.

Es en este contexto en el que surge la gobernanza territorial como un concepto y unas prácticas que, dado su carácter integrador, participativo y sistémico, parecen a priori especialmente adaptables para el tratamiento de los problemas de los espacios turísticos, temática a la que se dedica este artículo.

\section{Tipología de los procesos de gobernanza territorial aplicados a los destinos turísticos}

A partir de los planteamientos anteriormente expuestos, y dado que los años trans- 
curridos han permitido conocer un nutrido número de experiencias, es ya posible, como un marco de referencia que permita contextualizar mejor los casos de estudio elegidos, delimitar una propuesta de tipología de procesos de gobernanza territorial, atendiendo a su nivel de profundización en los rasgos esenciales del modelo. Según esto, se podrían distinguir:

a) Procesos de planificación "de arriba abajo", gerenciales o sin gobernanza, según los procedimientos de elaboración y aprobación de la planificación ya usuales, establecidos en la normativa (fases de aprobación, periodos de información pública). Son los detectables en la generalidad de los casos $y$, sin menoscabar su necesidad y legitimidad democrática, no parecen haber resuelto en el pasado de manera satisfactoria los problemas referidos en el epígrafe anterior.

b) Gobernanza superficial: serían aquellos casos en los que, aun partiendo de la correcta intención y sinceridad de los planteamientos de las autoridades locales impulsoras del proceso, y pese a la celebración formal de procedimientos característicos de la gobernanza (Ilamamiento institucional a la participación, convocatoria de grupos de trabajo de agentes locales, etc.), en la práctica son dichas autoridades locales las que condicionan la totalidad del proceso según sus concepciones preconcebidas (Martínez y Rosende, 2011); ya sea por debilidad o desarticulación de la sociedad civil, incapaz de ser parte activa participante en la toma de decisiones, o ya sea por desistimiento de la misma ante la frustración generada por anteriores experiencias de participación finalmente truncadas o deformadas.

c) Gobernanza desvirtuada: sería un agravante de la situación anterior, en la que todo el proceso formal de participación se diseña y conduce con el objetivo de dotar de legitimidad a un modelo territorial impulsado desde centros de decisión ajenos al territorio, pero de gran capacidad económica, poder de negociación e influencia mediática, que previamente han establecido con las autoridades locales las condiciones del modelo territorial funcio- nal a sus intereses. Con ello, el (mal) denominado proceso de gobernanza queda reducido a una campaña planificada de movilización de la opinión pública a favor del citado modelo, diluyendo las posibles opiniones contrarias a este (como resulta bien conocido, este tipo de situaciones no han sido infrecuentes como estrategia para facilitar la implantación de macroproyectos turístico-residenciales en el litoral, o grandes infraestructuras asociadas a estos). A este respecto, hay que recordar que, en principio, la gobernanza implica solo un modo de ejercer la acción de gobierno, pudiéndose hablar de "mala gobernanza" si se utiliza mal este modo de gobernar o si su resultado no es la gobernabilidad, entendida esta como el cumplimiento de las normativas, la capacidad para resolver conflictos, o la aceptación por parte de todos los sectores sociales de las reglas de juego institucionales encaminadas al logro del bien común (Pascual y Godás, 2010).

d) Gobernanza truncada: en este caso el proceso de gobernanza se desarrolla de manera coherente respecto a sus principios rectores, dando como resultado la plasmación de la participación consensuada de la sociedad local en un documento o plan, en el que quedan establecidos los rasgos esenciales del modelo territorial deseable a medio-largo plazo. Sin embargo, el proceso queda detenido o truncado en ese punto, por agotamiento del impulso inicial o por cambios en la composición política de la autoridad interviniente, no continuándose el proceso en el seguimiento de las medidas derivadas del plan, o directamente en la no aplicación o inobservancia de este ${ }^{6}$.

e) Gobernanza plena: representaría un auténtico "empoderamiento" por parte de

6 Un ejemplo nítido de esta casuística en el área de la costa de Cádiz tomada como ámbito de estudio para este artículo, sería la no aplicación de las determinaciones sobre limitaciones al crecimiento residencial aprobadas en el Plan Estratégico de Turismo del municipio de Tarifa (2007), ignorado (aunque no derogado) por las corporaciones locales posteriores. Ejemplo que se detallará en el apartado cuarto. 
la sociedad local, que participaría activamente tanto en la elaboración de la planificación territorial-turística como en el posterior seguimiento de la aplicación de la misma, permaneciendo activa en cuanto a la plasmación del modelo territorial consensuado, más allá del corto-medio plazo; modelo que irá impregnando el resto de actuaciones de la política local en lo relativo al territorio (movilidad, paisaje urbano, conservación y gestión de recursos, puesta en valor turístico, etc.). Lógicamente es más un objetivo óptimo que una realidad mensurable, si bien puede entenderse, con las lógicas prevenciones, que el caso de Conil de la Frontera (por la duración en el tiempo de los procesos estudiados y la extensión temática de estos) puede englobarse en esta categoría, como se detallará en los epígrafes posteriores.

\section{El caso de Conil de la Frontera: la continuidad de un proceso de planificación plasmado en la renuncia a la urbanización del frente litoral}

En términos muy sintéticos y descriptivos, la realidad territorial-turística de Conil de la Frontera (véase mapa de situación del ámbito de estudio en Figura $N^{\circ} 1$ ) se puede presentar exponiendo que su población de derecho se cifra en unos 21.900 habitantes, Ilegando en verano a contabilizar una población flotante de entre 80.000 y 90.000 personas, frente a una planta hotelera de unas 4.800 plazas (a las que hay que sumar unas 6.000 plazas en campamentos turísticos); y con una tradición predominante de vacaciones veraniegas de larga duración de demanda regional.

Figura $\mathrm{N}^{\circ} 1$

Mapa de situación del ámbito de estudio

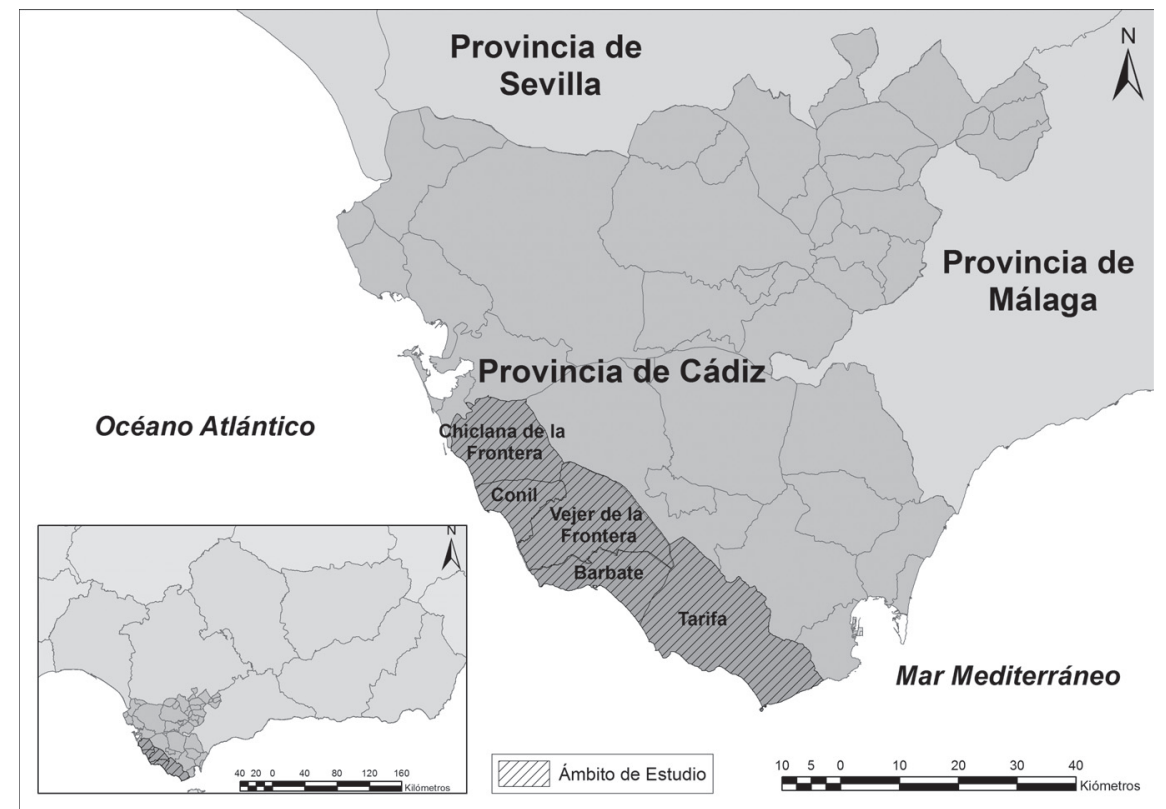

Fuente: Elaboración propia.

Asimismo, en los últimos años, en especial desde la apertura de la autovía A-48, se detecta una intensa presión urbanística sobre el suelo, derivada de la progresiva integración de la localidad en los flujos de la aglomeración urbana de la Bahía de Cádiz, así como de la expansión de la vivienda vacacional, de la agricultura y del turismo. Junto a ello, 
puede señalarse la reciente introducción de nuevos modelos de aprovechamientos turísticos, basados en la imagen de singularidad paisajística y cultural del área, dirigidos a segmentos de mercado con mayor capacidad de gasto y menor estacionalidad.

Lo más destacable de este caso, que ha sido estudiado a partir del análisis de documentos de planificación aprobados, así como con la realización de entrevistas a técnicos redactores de los mismos y agentes públicos locales (además de la cuantificación del proceso de urbanización a través de ortofotografías, como se detallará en el apartado quinto), es la continuidad del proceso planificador mediante diferentes figuras e instrumentos, a lo largo de más de una década, con los mismos responsables políticos y técnicos, y con una marcada coherencia interna en las líneas de actuación aprobadas y desarrolladas.

Desde el propio discurso público de las autoridades locales se define el proceso como una práctica de "planificación estratégica integrada de un destino turístico sostenible", en el seno de la cual se pueden detectar manifestaciones de planificación estratégica, urbanística, ambiental y turística.

Los rasgos más destacables de este proceso de planificación, que entroncan con las temáticas tratadas en esta investigación, serían:

- Se plantea como objetivo del conjunto del proceso orientar el modelo territorialturístico hacia lo que denomina "actividad turística productiva" (Plan Estratégico Conil 2012), es decir, la reglada, frente a la segunda residencia de uso estacional.

- Se marca como elemento integrante expreso del proceso de planificación lograr el apoyo social a medidas muy infrecuentes en el contexto del litoral español de las últimas décadas ${ }^{7}$ (tales como desclasifi-

\footnotetext{
7 En este sentido, son muy escasos los casos de actuaciones de desclasificación de suelo urbanizable y su paso a no urbanizable en el frente litoral, únicamente pueden citarse algunos limitados ejemplos derivados de las Directrices de Ordenación Territorial de las Islas Baleares, de 1999, y del Plan Director Urbanístico del Sistema Costero Catalán, de 2005 (véase como valoración
}

cación de suelo urbanizable en el borde costero, o elevación del nivel de protección del patrimonio natural por iniciativa municipal, como luego se ampliará). La participación activa en la planificación de agentes públicos y privados locales sitúa este ejemplo en el marco teórico de la gobernanza territorial anteriormente expresado.

El proceso de planificación presenta como hitos esenciales los siguientes:

- Comienza con un Plan Estratégico de Desarrollo Turístico en 1997.

- Plan General de Ordenación Urbana, cuya elaboración se inicia en 1996 y finalmente culmina con la aprobación definitiva en 2005.

- Plan de Excelencia Turística, desarrollado entre 1998 y 2000

- Plan Estratégico Conil 2012, aprobado en 2002.

- Plan de Ordenación del Litoral de Roche, aprobado en 2004.

Los dos planes de mayor interés para el análisis aquí realizado serían el Plan Estratégico Conil $2012^{8}$ y el P.G.O.U. A continuación se destacan sus características esenciales.

\section{- $\quad$ El Plan Estratégico Conil 2012}

Como corresponde a su modalidad de planificación, es un documento orientado a realizar una reflexión estratégica general sobre las grandes líneas a seguir por el municipio en la década siguiente, y su elaboración y aprobación está marcada por un amplio proceso de participación social, por lo que puede afirmarse que se ajusta al enfoque de gobernanza territorial anteriormente enunciado. Asimismo hay

de estas medidas Rullán, 2011: 285-287 y 292-293), o el actual intento, aún no plenamente definido, del Plan de Protección del Corredor Litoral de Andalucía.

8 Cabe destacar que la dirección técnica tanto de este plan como del Plan de Excelencia Turística fue desarrollada por la empresa consultora en planificación "Asistencias Técnicas Clave, S.L.", cuyo asesoramiento debe considerarse fundamental para entender el proceso. 
que destacar que coincide en su elaboración con las fases finales de redacción del P.G.O.U., con cuyas propuestas se interrelaciona de forma apreciable.

Los objetivos declarados de este Plan Estratégico, en notable consonancia con los planteamientos buscados en esta investigación, fueron:

- "Crecer en función de los recursos y la calidad de vida.

- Mantener el patrimonio natural y cultural.

- Aprovechar las potencialidades existentes para generar empleo estable y de calidad

- Mejorar y modernizar los mecanismos de cohesión y participación social."

- Asimismo, en el documento aparecen declaraciones tan clarificadoras del espíritu que anima el proceso como las siguientes:

“En Conil no pretendemos crecer a costa de perder lo que se ha conseguido mediante el esfuerzo de muchas generaciones. Creemos que en el mundo actual no todos los territorios tienen que ser iguales y que existen oportunidades de creación de riqueza y empleo para los lugares que sean capaces de valorizar sus diferencias y convertirlas en argumentos de interés para sus productos (el campo y la pesca) y para la visita (turismo todo el año)."

"Como alternativa a este modelo basado en la diferencia y el patrimonio se contempla el fuerte desarrollo inmobiliario y banal, propio de otros muchos lugares del litoral español".

Así pues, como puede observarse, el Plan Estratégico aparece marcado por una renuncia voluntaria al crecimiento masivo de la urbanización y el desarrollo inmobiliario, apostando frente a ello por un desarrollo basado en la diferenciación y el mantenimiento de los rasgos singulares del territorio; señalándose en el propio texto lo excepcional de esta orientación en el contexto español del momento. Lo más significativo, sin embargo, es que estas intenciones no quedan reducidas a una mera declaración sin consecuencias reales, sino que se trasladan al planeamiento urbano en proceso paralelo de elaboración, como se detallará a continuación.
- El Plan General de Ordenación Urbana. Es aprobado definitivamente en 2005, si bien el proceso de elaboración arranca varios años antes, coincidiendo en buena parte de sus fases esenciales de toma de decisiones con el Plan Estratégico. Puede afirmarse que algunas de sus propuestas fundamentales representan la plasmación física sobre el territorio de los resultados del proceso de participación social anteriormente comentado. En este sentido, pueden destacarse como rasgos sobresalientes del P.G.O.U. de cara a los objetivos de esta investigación los siguientes:

- Otorga prioridad expresa al aprovechamiento hotelero frente al residencial en el borde costero.

- Protege tramos de costa como espacios abiertos (playa de Castilnovo y El Palmar, al sur del núcleo). La actuación sobre este tramo continuó posteriormente a la aprobación del P.G.O.U., procediendo el propio Ayuntamiento a solicitar su declaración como Espacio Natural Protegido a la Junta de Andalucía, con el objetivo expreso de garantizar su exclusión de presiones urbanizadoras en el futuro. En este sentido, en una declaración pública del alcalde de la localidad se afirma: "Hemos declarado zona protegida la franja litoral que va desde Conil al término de Vejer, que es donde está Castilnovo. Incluso hemos pedido a la Junta que la declare paraje natural porque entendemos que tiene que haber zonas de la costa libres de edificación. Buscamos, en definitiva, un distintivo único y especial para que una parte del litoral conileño se declare de protección especial. Ese es el atractivo y el futuro del turismo" (El País, 23-82005). Cabe señalar lo excepcional del hecho que desde una autoridad local se inste a una instancia superior competente la declaración de una parte de su término municipal como Espacio Natural Protegido, precisamente como garantía para preservarla de la urbanización, así como que la Consejería de Medio Ambiente de la Junta de Andalucía no ha accedido a dicha solicitud.

- Lo más relevante a los efectos aquí tratados, el P.G.O.U. desclasifica unos tres millones de metros cuadrados edificables de propiedad municipal, al norte del 
núcleo (Acantilado de Roche), que anteriormente estaban clasificados como suelo urbanizable programado, pasando a no urbanizable de protección especial (véase localización de la parcela desclasificada en el mapa de la Figura $\mathrm{N}^{\circ} 2$ ). Es esta una medida exclusivamente de iniciativa municipal, sin estar obligada a ello por ningún tipo de normativa ambiental o de ordenación del territorio de ámbito supramunicipal, lo cual la convierte en un ejemplo con muy escasos precedentes en el litoral español, en especial en un entorno, como el referido, de muy elevado valor en el mercado de suelo.

A modo de síntesis, es preciso señalar la trascendencia del modelo general adoptado,

Figura $\mathrm{N}^{\circ} 2$

Mapa de clasificación de suelo del municipio de Conil de la Frontera, con indicación de parcela reclasificada

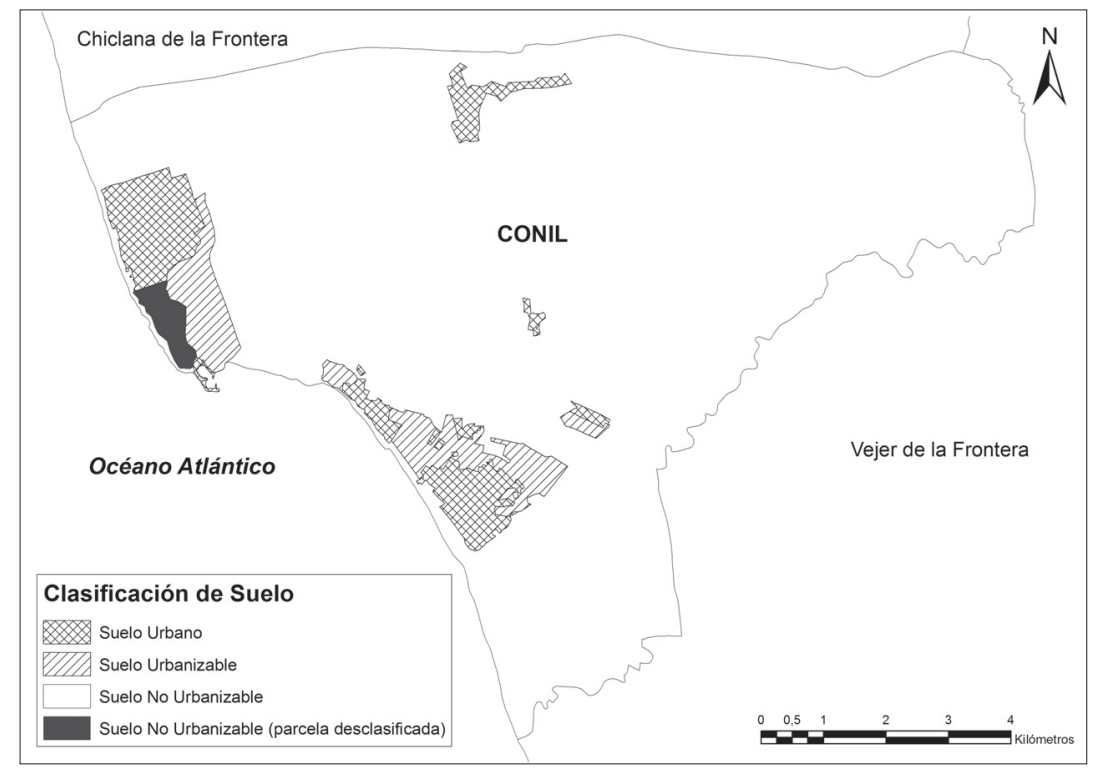

Fuente: Elaboración propia a partir de P.G.O.U. de Conil de la Fra.

por su excepcionalidad en el escenario andaluz y español, y de las medidas concretas tomadas de forma coherente con aquel. Igualmente es destacable que estas orientaciones hayan sido aceptadas y respaldadas por el conjunto de la sociedad local, a pesar del modelo expansionista que en esos años, y aún en la actualidad, imperaba en municipios limítrofes. Dicha aceptación y apoyo social, si bien no puede medirse con metodologías de carácter cuantitativo, sí puede apreciarse en aspectos cualitativos, tales como:

- El respaldo electoral continuado recibido por el equipo de gobierno municipal impulsor del proceso, que ha seguido gobernando la localidad desde los años noventa hasta hoy.

- La continuidad del impulso planificador, plasmado en otros instrumentos de iniciativa municipal coherentes en líneas generales con las estrategias señaladas (Plan de Recuperación del Enebro Marítimo, Plan de Ordenación del Litoral de Roche, Plan Especial de Ordenación y Recuperación del Casco Histórico); e incluso con ejemplos destacables de iniciativas de gobernanza en otros ámbitos ajenos al turismo (como el diseño y solicitud de declaración de una Reserva Marina de Interés Pesquero, que sería la primera de 
Andalucía y segunda de España, realizada de forma conjunta entre la Cofradía de Pescadores de la localidad y la asociación Ecologistas en Acción).

Resulta difícil, dada la propia complejidad de la temática y el hecho de que es un proceso relativamente reciente y que continúa en la actualidad, poder ofrecer resultados nítidos que demuestren el nivel de éxito global alcanzado con las orientaciones adoptadas. No obstante, sí pueden mostrarse datos significativos que ya se van conociendo y pueden orientar las valoraciones sobre dicho proceso:

- En primer lugar, la ocupación media anual de la planta hotelera del municipio, indicador representativo de la competitividad global de un destino y del buen funcionamiento de su tejido empresarial turístico, muestra para el último año del que existen datos detallados (2011) que el municipio de Conil presenta, con un $58,04 \%$, el tercer valor más elevado de Andalucía, solo por detrás de municipios con la tradición y penetración en mercados externos de Benalmádena y Torremolinos (según la Encuesta de Ocupación Hotelera del I.N.E.). Ello muestra la competitividad de este tejido turístico en términos de rentabilidad empresarial.

- En segundo lugar, el hecho de presentar unos niveles de saneamiento de la hacienda local que pueden ser calificados de destacadamente positivos en el contexto en el que se ubica. De esta forma, si se considera la deuda municipal por habitante como un indicador válido de esta cuestión, se constata, según los datos del Ministerio de Hacienda, que Conil, con una deuda municipal de 389 euros por habitante en el año 2012, presenta la segunda mejor posición, solo superada por Almuñécar, en el conjunto de municipios litorales andaluces de más de 20.000 habitantes, muy por debajo de la media de éstos, establecida en $1.013 € /$ hab. Este dato debe ser considerado de gran interés, en tanto que, si se tiene en cuenta la renuncia de este municipio a la expansión urbanística en la línea de costa durante la última década, cuestiona la tradicional afirmación de que el crecimiento de la urbanización, con las cesiones y generación de ingresos fiscales que genera, ha sido un instrumento obligado para la financiación de los ayuntamientos españoles; mostrándose así la posibilidad de estrategias alternativas a las que han predominado de forma generalizada en la gestión municipal andaluza y española.

\section{El caso de Tarifa: la singularidad de un plan estratégico de turismo orientado a la limitación del crecimiento urbano y su posterior inaplicación}

Al igual que se hizo en el caso anterior, y como breve presentación de la experiencia, la realidad territorial-turística de Tarifa se puede sintetizar exponiendo que su población actual es de 17.700 habitantes de derecho y cuenta con 2.375 plazas hoteleras. Su rasgo territorial distintivo estriba en ser el punto más meridional del continente europeo, con una posición geoestratégica en el estrecho de Gibraltar que explica su historia así como su patrimonio natural y cultural (migraciones de aves y cetáceos como recursos turísticos, proximidad del puerto de Tánger, en Marruecos, declaración del Parque Natural del Estrecho). Asimismo, presenta $38 \mathrm{~km}$ de playas, algunas de excepcional calidad, y un elemento singular, la frecuencia y potencia del viento, que ha condicionado su escaso desarrollo como destino tradicional de sol y playa así como su presencia actual como destino reconocido de deportes acuáticos de viento, con gran capacidad de penetración en los segmentos internacionales de demanda de esta modalidad.

El documento de planificación cuyo interés ha llevado a considerar este caso en la investigación es el Plan Estratégico de Desarrollo Turístico "Tarifa 2015". Se trata de una experiencia de planificación desarrollada durante los años 2006 y 2007, a través de una metodología de elaboración basada en la constitución y trabajo en común de grupos de opinión representativos de los diferentes agentes locales, públicos y privados, integrantes del sistema turístico local; cuyas conclusiones fueron aprobadas por el pleno municipal y por tanto asumidas por el equipo 
de gobierno impulsor del proceso. Este Plan contó asimismo con una fuerte impronta territorial en sus debates y resoluciones, por lo que puede considerarse un caso de interés a analizar desde el enfoque de la gobernanza territorial. Los rasgos más destacables a nuestros efectos de esta experiencia han sido los siguientes:

- Como idea inspiradora de todo el Plan, la estrategia de basar el desarrollo turístico de la localidad en la valorización de la singularidad excepcional y la diferenciación del territorio en el que se asienta. Por ello el reconocimiento y tratamiento del espacio turístico adquiere un nítido protagonismo en la redacción del Plan, con referencias expresas a la necesidad de coordinar las determinaciones del mismo con las derivadas de la planificación física, reflejadas en el planeamiento urbanístico.

- La reiterada distinción entre oferta residencial y oferta turística comercial o turística propiamente dicha, cuyas interrelaciones se constituyen en la práctica en el tema central del Plan. De esta forma, se llega a afirmar de forma expresa en el Diagnóstico del mismo: "La principal amenaza (...) es la generalización de urbanizaciones residenciales que generan ciudades 'vacías' durante la mayor parte del año e inhabitables durante la época estival". En este sentido, en el propio texto se refleja un cuadro diagnóstico que sintetiza las ventajas e inconvenientes de ambas opciones, afirmando que la opción residencial presenta como principales problemas "la lógica consuntiva de suelo; la concentración estacional; y la presión sobre elementos territoriales"; apareciendo como gran ventaja apreciable sobre la opción empresarial-hotelera la obtención de beneficios empresariales y sociales (empleo) con mayor rapidez a corto plazo, así como el hecho de que es más accesible a los operadores locales. Por el contrario, se apuntan como ventajas diferenciales de la opción comercial-hotelera sobre la residencial su mayor capacidad de generación de empleos y rentas, de hecho, se cita un cálculo estimativo según el cual una misma porción de terreno dedicada a uso hotelero generaría a mediolargo plazo ocho veces más empleo y doce veces más renta que si es destinada a segundas residencias, al mismo tiempo que permite una mejor valorización del paisaje y el medio natural.

- En coherencia con el diagnóstico anterior, se plantea como uno de los objetivos específicos del Plan Estratégico "Otorgar prioridad al alojamiento no residencial como fórmula para reducir la dependencia de la temporada veraniega" (Objetivo operativo $\mathrm{N}^{\circ} 2$ ).

- Este objetivo se concreta en la adopción de medidas para "el encauzamiento de las inercias urbanizadoras", mediante el planteamiento de tres modelos o estimaciones de plazas en segunda residencia para el futuro año 2015. Estos modelos se precisan y cuantifican en el documento, siendo denominados:

- Modelo tendencial: proyección al futuro en ausencia de otras regulaciones distintas a las existentes en el momento, con una estimación de 43.000 plazas, cuando en 2007 eran 17.500.

- Modelo patrimonial: con aplicación estricta de criterios de conservación, con una estimación de 18.200 plazas. El Plan lo considera óptimo, pero en condiciones que no parecen darse, dada la necesidad de financiar operaciones de adecuación.

- Modelo combinado: con equilibrio entre los criterios de carácter turístico empresarial y los mínimos necesarios de desarrollo residencial "para financiar las operaciones de adecuación de cada sector y de la mejora de la calidad total del municipio". La estimación de plazas en segunda residencia en este modelo se establece en 23.400, y es el elegido en el Plan.

- Hay que destacar que la aprobación de este máximo de 23.400 plazas residenciales para el 2015 constituyó la determinación más debatida y cuestionada del Plan, ya que en la práctica, dadas las viviendas ya previstas en urbanizaciones aprobadas, significaba el establecimiento de una moratoria para la construcción de segundas residencias en el municipio hasta el 2015. De esta forma, un documento de planificación turística, además elaborado como su nombre indica mediante un am- 
plio proceso de participación, se intenta constituir de hecho, aunque no pudiera serlo de derecho, en condicionante para el planeamiento urbanístico, ya que el Plan Estratégico fue aprobado por el pleno municipal en 2007, siendo así una referencia obligada en los trabajos de elaboración del nuevo P.G.O.U. que estaban teniendo lugar en esos momentos, y que manejaban opciones de construcción más expansionistas que la aquí referida. Es precisamente este intento de vincular la redacción de un P.G.O.U. a un Plan Estratégico de Desarrollo Turístico, convertido en un instrumento indirecto de limitación del crecimiento urbanístico, lo que hace de este ejemplo un caso singular en el escenario de la planificación de destinos turísticos en España.

Sin embargo, hay que señalar que tras la aprobación de un Avance del P.G.O.U. en 2004, de este Plan Estratégico en 2007, y de una Adaptación parcial en 2010 del PGOU vigente (de 1990) a la Ley de Ordenación Urbanística de Andalucía, aún en 2013 no ha culminado la redacción del nuevo P.G.O.U., por lo que no puede valorarse el grado de vinculación con lo aprobado en dicho Plan Estratégico. Por último, debe apuntarse que con los cambios acaecidos desde entonces en el equipo de gobierno municipal, estas orientaciones han quedado en suspenso, a la espera de futuras decisiones al respecto; si bien actuaciones como la aprobación en mayo de 2012 de un Plan Parcial que prevé la creación, junto a un número estimable de plazas hoteleras, de 350 nuevas viviendas en las proximidades de la playa de Valdevaqueros, apuntan a la desestimación de las orientaciones estratégicas contenidas en el Plan aquí comentado que, de hecho, pese a no haber sido derogado, ha desaparecido en la práctica como referencia activa de la vida pública municipal, por lo que no resulta inadecuado calificar este caso como un ejemplo de gobernanza territorial truncada. A pesar de todo, ello no resta interés como caso de estudio a esta experiencia, en especial en lo relativo a la metodología de participación y concertación con la que fue desarrollada, así como en su capacidad de articular opiniones e intereses muy diversos en torno al modelo territorial, y por tanto turístico, deseable para el destino a medio-largo plazo.

\section{Resultados cuantitativos del análisis del crecimiento urbanizador: el caso de Conil de la Frontera en el contexto del ámbito de estudio}

Finalmente, tras la presentación y análisis anteriormente realizados de las estrategias y medidas adoptadas en el municipio de Conil de la Frontera (en tanto que caso más representativo para la temática de la gobernanza territorial aquí tratada), corresponde en este apartado realizar una evaluación de los resultados contrastables y medibles en el territorio, en lo relativo al incremento de la superficie ocupada por la urbanización y/o la edificación, y su comparación con otros municipios próximos en la costa de Cádiz (Chiclana de la Frontera, Vejer de la Frontera, Barbate y Tarifa), evaluación realizada a partir de la metodología expuesta en el apartado introductorio.

Los resultados del estudio realizado se reflejan en los mapas de las Figuras $\mathrm{N}^{\circ} 3$ y $\mathrm{N}^{\circ} 4$, así como en el Cuadro $N^{\circ} 1$, referido a la totalidad de la superficie de los términos municipales, y el Cuadro $\mathrm{N}^{\circ} 2$, circunscrito a los crecimientos experimentados en la franja de los cinco primeros kilómetros desde la línea de costa.

En una primera aproximación puede apreciarse la aceleración del proceso de ocupación en el periodo 2002-2006, coincidiendo con los años álgidos del ciclo expansivo a nivel general, este crecimiento ha sido destacable en Conil (8,01\%), si bien hay que señalar que en buena parte se debe al escaso dinamismo anterior y al desarrollo de suelos ya previamente clasificados como urbanizables; así como el hecho de que el trabajo de campo ha mostrado que la mayor parte de este crecimiento se ha dirigido a rellenar intersticios en la periferia externa del núcleo tradicional, con predominio de equipamientos públicos, zonas comerciales, suelo industrial (Polígono Industrial La Zorrera) y promociones de viviendas públicas para alquiler dirigidas a la población local, con una limitada presencia de nuevos usos residenciales vacacionales.

Igualmente destaca la práctica paralización en el 2006-2008-2010, muestra del 
Figura $\mathrm{N}^{\circ} 3$

Evolución de la ocupación del suelo y crecimiento de la urbanización por años en Conil de la Frontera (Cádiz) (1998, 2002, 2006 y 2008)

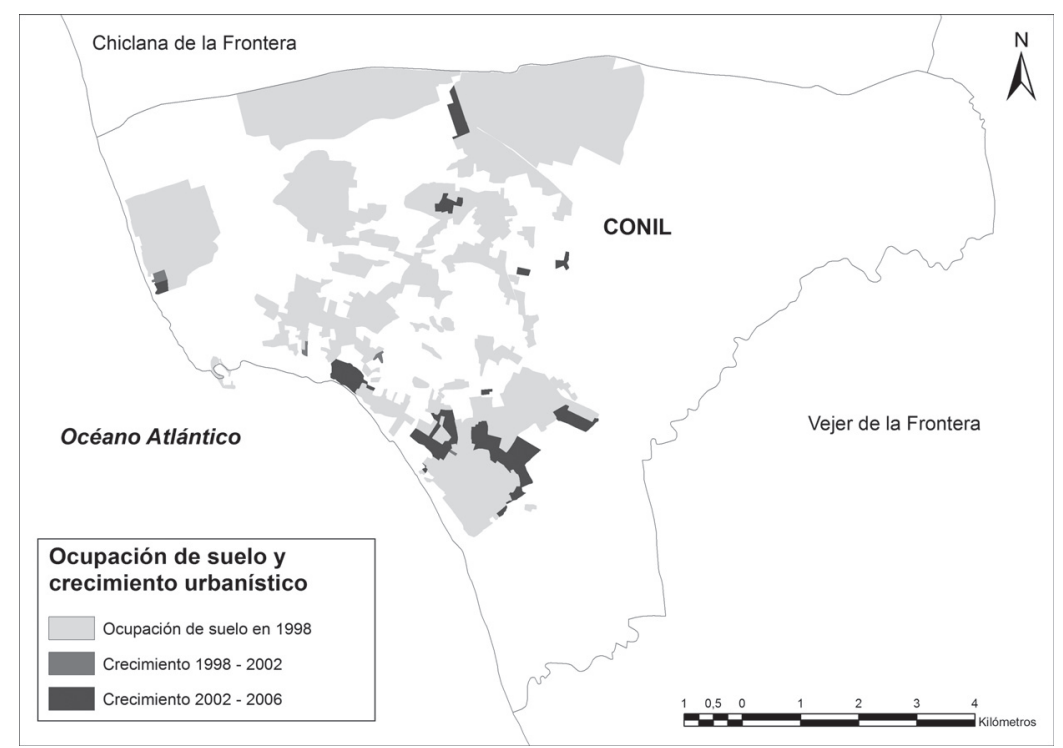

Fuente: Elaboración propia.

Figura $N^{\circ} 4$

Evolución de la ocupación del suelo por años y por clases de suelo en Conil de la Frontera (Cádiz). $(1998,2002,2006$ y 2008)

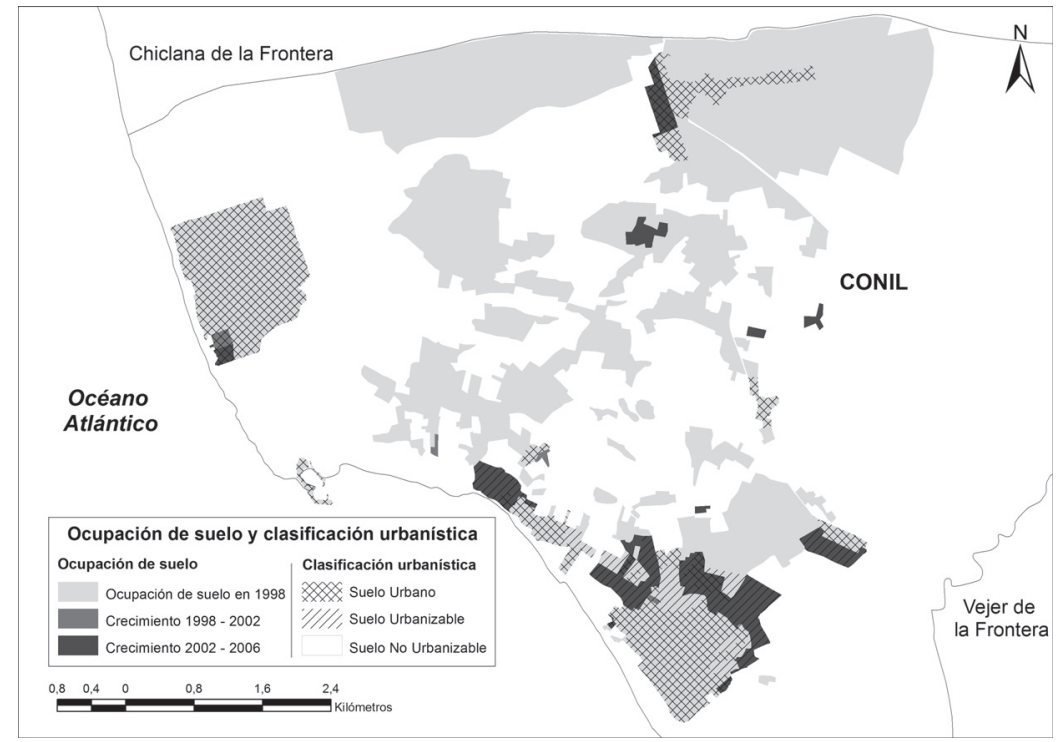

Fuente: Elaboración propia. 


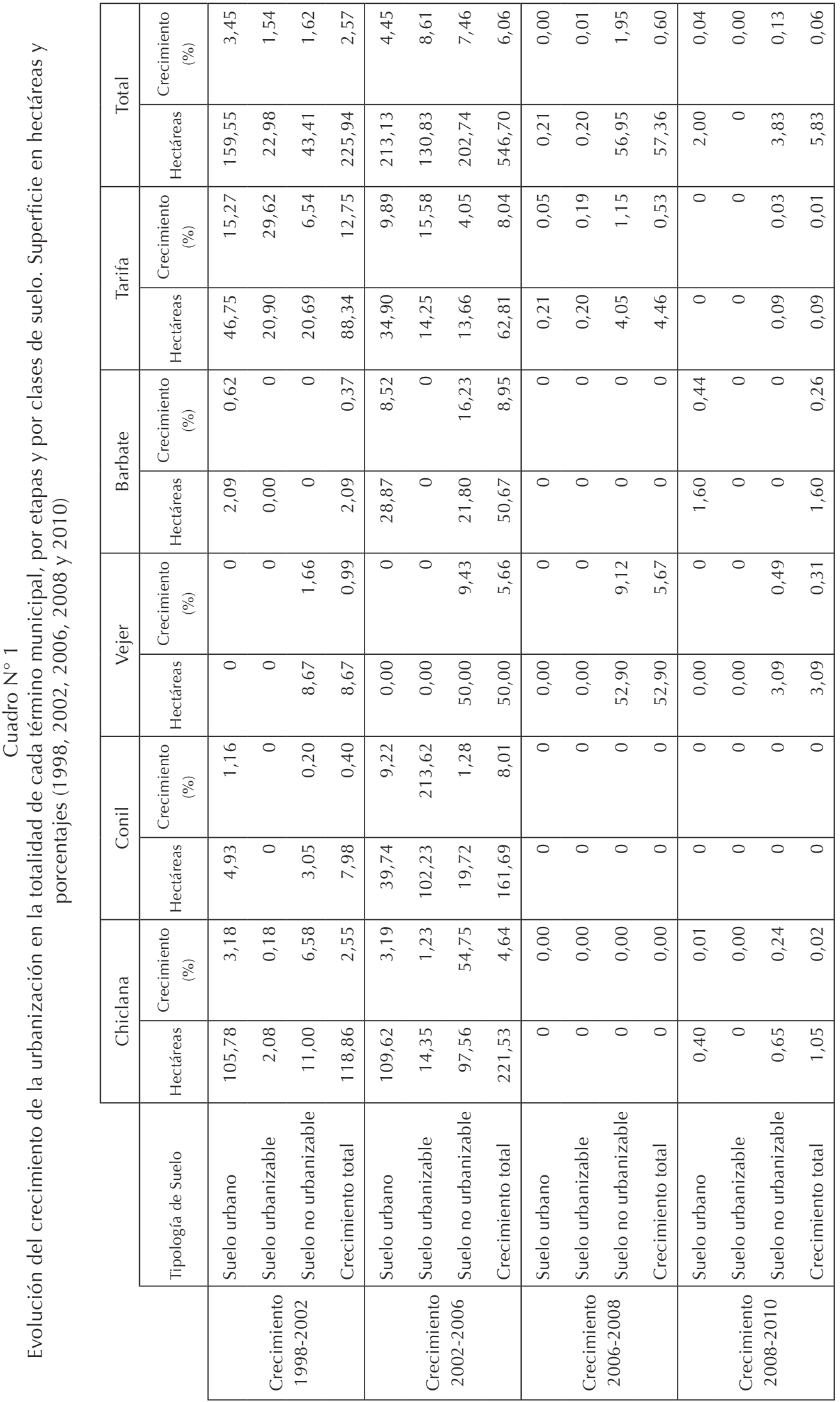




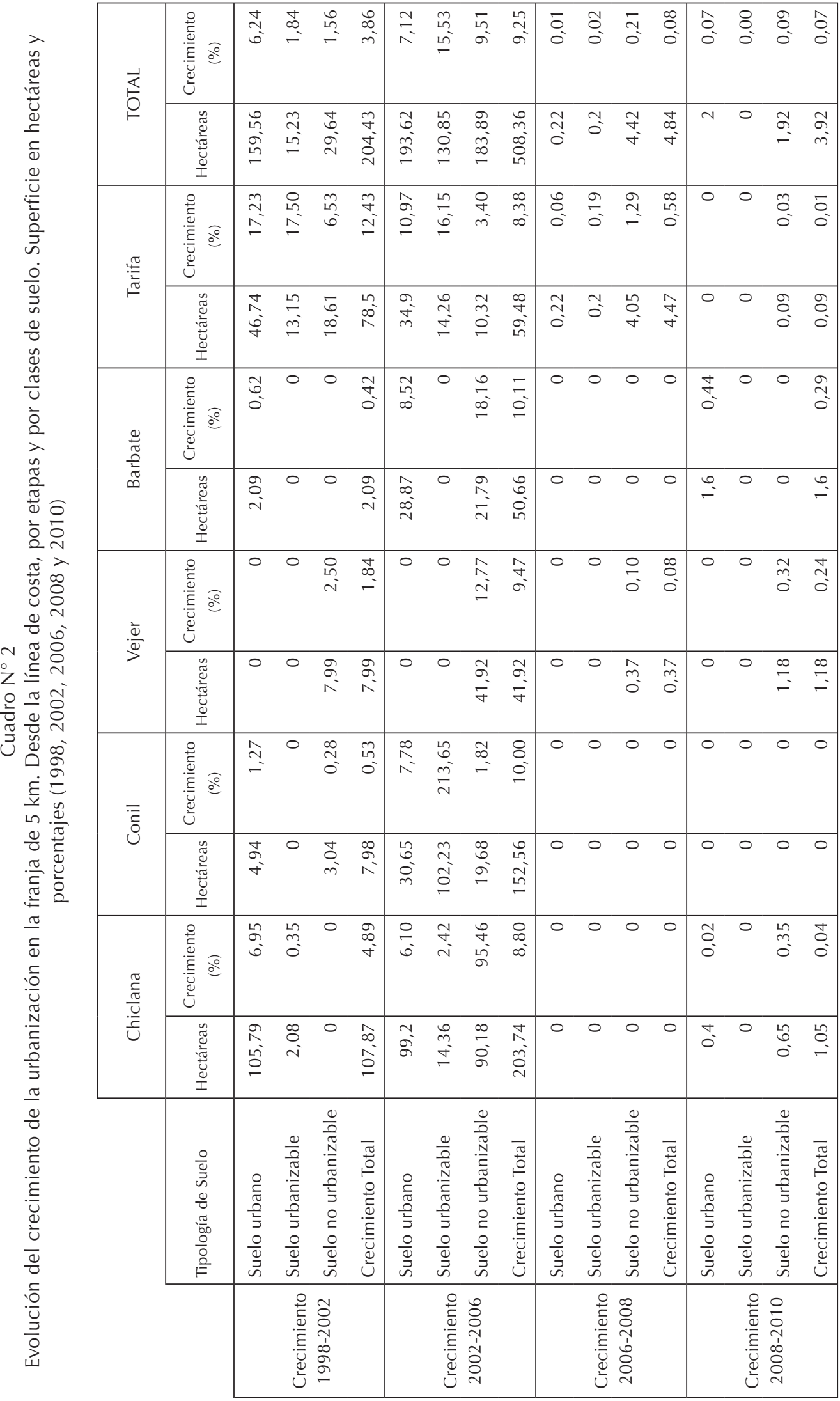


colapso del sector de la construcción generalizado en el litoral andaluz y español a partir del estallido de la crisis, y que, como puede apreciarse en las dos tablas, es un fenómeno extendido en todo el ámbito de estudio. Asimismo, se aprecia la expansión del fenómeno de las construcciones ilegales en suelo no urbanizable, que, si bien en Conil constituyen en buena parte una herencia de décadas pasadas que han quedado alejadas de la línea de costa y no alcanzan las magnitudes de los municipios limítrofes, siguen apareciendo como un problema territorial de gran magnitud, como muestra la cartografía (a este respecto destaca el vecino municipio de Chiclana, uno de los ejemplos más graves de esta problemática en Andalucía, con un incremento de la superficie ocupada por edificaciones en S.N.U. de casi 110 hectáreas en el periodo de 1998 a 2006, de las que 97,56 corresponden al segundo cuatrienio, en el que el crecimiento del $54,75 \%$ en la superficie total ocupada por estas construcciones revela nítidamente el grado de descontrol urbanístico alcanzado en los años culminantes del último ciclo expansivo).

No obstante, el análisis de mayor interés estriba en comparar esta evolución con la experimentada en otros ámbitos territoriales. Así, según datos conocidos de otros trabajos (Villar, 2012), para el conjunto del litoral andaluz en el periodo comprendido entre 1998 y 2007 se ha ocupado el $20 \%$ de la superficie urbanizada a lo largo de la historia. Ajustando más la comparación, y según la misma fuente, en el litoral atlántico andaluz (ámbito al que pertenece el municipio estudiado) el porcentaje correspondiente a este periodo es del 15\%. En el caso de Conil, según el cálculo efectuado para este artículo, la superficie ocupada en esos años constituye el 9,57\% del total de lo urbanizado (se equipara el resultado de 2007 al de 2006, al no haberse producido crecimiento); siendo asimismo la menor de su entorno con la excepción de Barbate $^{9}$ (Chiclana: 12,37\%; Vejer: 10,27\%;

\footnotetext{
9 Hay que señalar para el caso de Barbate que el reducido crecimiento de la urbanización en los años considerados no ha sido debido tanto a una voluntad de restringir el mismo por parte de las autoridades locales sino al hecho de tener buena parte del término calificada como zona militar.
}

Barbate: 9,53\%; Tarifa: 17,83\%), y marcadamente inferior al promedio conjunto del ámbito de estudio (12,01\%). De esta forma, puede afirmarse que el impulso experimentado por el proceso de ocupación en Conil, si bien puede estimarse considerable, ha sido sensiblemente inferior al experimentado por el conjunto de espacios litorales de su entorno geográfico.

\section{Conclusiones}

Se constata la necesidad de buscar nuevas fórmulas para la planificación y gestión territorial de los espacios turísticos, en especial ante las carencias mostradas por los modelos tradicionales para controlar, o al menos racionalizar, el desmesurado crecimiento de la urbanización en el último ciclo expansivo del sector de la construcción.

En este escenario se va consolidando el enfoque de la gobernanza territorial, que pone el acento en la necesidad de comprender e incidir en las dinámicas socioeconómicas de los territorios concretos, resultado de la actuación de redes formales e informales de agentes, dinámicas que finalmente van a conformar el territorio resultante.

La investigación ha permitido identificar casos concretos en los que, a diferencia de la tendencia generalizada constatable en los últimos años, se aprecian estrategias nacidas en el ámbito local que rechazan expresamente la identificación desarrollo turístico-crecimiento inmobiliario, estableciendo para ello limitaciones a la expansión de la urbanización. Los ejemplos en los que se ha centrado este artículo han sido los de Conil de la Frontera y Tarifa, en la costa de Cádiz, analizando con mayor detalle el caso de Conil, en tanto representa, como las páginas anteriores han mostrado, la experiencia más relevante en

\footnotetext{
Asimismo, en la actualidad se está acometiendo en dicho municipio una iniciativa de ocupación de suelo de gran magnitud, como es el campo de golf del Següesal Golf Resort (Acuerdo de Declaración de Interés Turístico publicado en Boletín Oficial de la Junta de Andalucía de 4-8-2011), con una previsión de construcción de 450 viviendas y 956 apartamentos turísticos (Villar y Fernández, 2013).
} 
cuanto a orientación y duración de las estrategias señaladas.

Una vez cuantificado, a través de la utilización de ortofotografías de diferentes años, el crecimiento experimentado por la urbanización en el ámbito de estudio en la etapa reciente (1998-2010), puede afirmarse que en el término de Conil este ha sido sensiblemente inferior al mostrado por el conjunto del litoral andaluz o por el arco atlántico de dicho litoral. Y no parece aventurado concluir que esta singularidad es fruto de los procesos de planificación anteriormente citados, orientados hacia un modelo territorial-turístico basado en la limitación de los procesos constructivos en el litoral.

Los análisis realizados y resultados obtenidos muestran la presencia de estrategias de actuación que pueden calificarse como propias de una buena gobernanza territorial (lograda en buena parte en el caso de Conil, e iniciada y posteriomente suspendida en el caso de Tarifa); estrategias que se corresponden con la definición expresada en el marco teórico, según la cual la gobernanza territorial se basaría en la "puesta en práctica de formas de planificación y gestión de las dinámicas territoriales innovadoras y compartidas (caracterizadas por la relación, negociación y formación de consensos), respaldadas por multiplicidad de actores que comparten unos objetivos y conocen y asumen cuál debe ser su papel en su consecución" (Farinós, 2008). Esta correspondencia entre el concepto teórico y la realidad práctica se sustenta en tres elementos: 1) La definición del modelo territorial-turístico del municipio en procesos de planificación estratégica, con amplia participación de la población y agentes sociales locales, que Ilegan a consensos concretos, no generalistas, sobre cuáles son las opciones deseables de cara al futuro; 2) La coordinación e incluso vinculación de los resultados consensuados de dicha planificación estratégica con la planificación física o espacial del ámbito, concretada en el Planeamiento Urbano reglado normativamente, que asume el modelo generado en el proceso de planificación estratégica y lo concreta sobre el plano; 3) Por último, puede entenderse como ejemplo de buenas prácticas ya que dicho modelo territorial-turístico, nacido de la participación social y concretado en el Planeamiento Ur- bano, se sustenta en los principios de limitar el crecimiento urbanístico en el frente litoral y optar por la oferta reglada o comercial frente a la construcción masiva de segundas residencias, intentando evitar los conocidos problemas derivados de estas prácticas que se han señalado en el apartado introductorio.

De esta forma, con las debidas precauciones derivadas de la dificultad de aplicar indicadores verificables a procesos sociales de largo recorrido, no parece exagerado afirmar que casos como los analizados en esta investigación, en especial la experiencia de Conil de la Frontera, pueden ser mostrados como ejemplo de buenas prácticas en la búsqueda de estrategias de planificación y gestión de destinos turísticos alternativas a las usualmente practicadas en el litoral español. Estrategias que, con las carencias y limitaciones igualmente señaladas, intentan compatibilizar la participación ciudadana en un marco de gobernanza real, la sostenibilidad territorial plasmada en la renuncia a la urbanización del frente litoral, y el mantenimiento de una elevada competitividad conjunta del destino, reflejada en la rentabilidad del tejido empresarial turístico; todo ello en un contexto territorial, como es la costa de Cádiz y el litoral andaluz en general, en el que la expansión inmobiliaria en el último ciclo expansivo se postuló reiteradamente como la única orientación posible y viable para nuestros espacios litorales, dando como resultado la crisis integral de las estructuras económicas, sociales y territoriales que hoy podemos constatar.

\section{Referencias bibliográficas}

AGARWAL, S. Global-local Interactions in English Coastal Resorts: Theoretical Perspectives. Tourism Geographies, 2005, Vol. 7, No 4, p. 351-37.

ANTÓN, S. De los procesos de diversificación y cualificación a los productos turísticos emergentes. Cambios y oportunidades en la dinámica reciente del turismo litoral. Papeles de Economía Española, 2004, № 102, p. 316-333.

ANTON, S. y GONZÁLEZ, F. (coordinadores). A propósito del turismo. La construcción social del espacio turístico. Barcelona: Ediciones UOC, 2007. 

DE FUERTE PRESIÓN INMOBILIARIA. ANÁLISIS DE BUENAS PRÁCTICAS LOCALES EN LA COSTA DE CÁDIZ (ESPAÑA)

BRAMWELL, B. Mass Tourism, Diversification and Sustainability Development in Southern Europe's Coastal Regions. In: BRAMWELL, B. (editors). Coastal Mass Tourism. Diversification and Sustainability Development in Southern Europe. Clevedon: Channel View Publications, 2004, p. 1-31.

BRITTON, S. Tourism, capital and place: towards a critical geography of tourism, Environment and Planning D. Society and Space, 1991, N 9, p. 451-478.

CAPEL, H. Urbanización generalizada, derecho a la ciudad y derecho para la ciudad. En: Conferencia inaugural del XI Coloquio Internacional de Geocrítica. Scripta Nova: Revista Electrónica de Geografía y Ciencias Sociales, 2010a, Vol. XIV, No 331 (7). Disponible en Internet: http://www.ub.es/geocrit/sn/ sn-331/sn-331-7.htm

CAPEL, H. El urbanismo, la política y la economía (y viceversa). Una perspectiva comparada. Biblio 3W. Revista Bibliográfica de Geografía y Ciencias Sociales, 2010b, Vol. $X V, N^{\circ}$ 893. Disponible en Internet: http:// www.ub.es/geocrit/b3w-893.htm

COMISIÓN EUROPEA (CE). La Gobernanza Europea: Un Libro Blanco. COM (2001) 428 final, DOCE C-287, de 12 de octubre de 2001. Disponible en Internet: http://eurlex.europa.eu/LexUriServ/ site/es/com/2001/ com2001_0428es01.pdf

CONRADY, R. \& BUCH, M. (editors). Trends and Issues in Global Tourism. Berlin: Springer, 2007.

DREDGE, D. Leisure lifestyles and tourism: socio-cultural, economic and spatial change in Lake Macquarie. Tourism Geographies, 2001, Vol. 3, N³, p. 279-299.

DUBUS, N.; HELLE, C. \& MASSON-VINCENT, M. De la gouvernance à la géogouvernance : De nouveaux outils pour une démocratie locale renouvelée. L'Espace Politique, 2010-1. Disponible en Internet: http://espacepolitique.revues.org/index1574.html\#sthash. XYeg9F9L.dpuf

ÉQUIPE MIT. Tourismes 2. Moments de lieux. Paris: Belin, Collection Mappemonde, 2004.
ÉQUIPE MIT Tourismes 3. La révolution durable. Paris: Belin, Collection Mappemonde, 2011.

EXCELTUR. Estudio de los impactos socioeconómicos, ambientales y sobre el empleo del actual modelo de desarrollo turístico español del litoral mediterráneo, Baleares y Canarias. Madrid: Área de Estudios e Investigaciones de Exceltur en colaboración con Deloitte, 2005.

FARINÓS, J. (coordinador). Governance of Territorial and Urban Policies from EU to Local Level. ESPON Project 2.3.2. Informe final del Proyecto ESPON 2.3.2, 2007. Disponible en Internet: http://www.espon.eu/export/ sites/default/Documents/Projects/ESPON2006Projects/PolicylmpactProjects/Governance/fr2.3.2_final_feb2007.pdf

FARINÓS, J. Gobernanza territorial para el desarrollo sostenible: estado de la cuestión y agenda. Boletín de la Asociación de Geógrafos Españoles, 2008, № 46, p. 11-32.

FAULKNER, B.; MOSCARDO, G. \& LAWS, $\mathrm{E}$. Tourism in the twenty-first century. Londres: Continuum, 2001.

FERNÁNDEZ-TABALES, A. y CRUZ, E. Análisis territorial del crecimiento y la crisis del sector de la construcción en España y la Comunidad Autónoma de Andalucía. EURE, 2013, Vol. 39, No 116, p. 5-37.

GARCÍA-BELLIDO, J. Por una liberalización del paradigma urbanístico español (III): El tsunami urbanístico que arrasará el territorio. Ciudad y Territorio. Estudios territoriales, 2005, No 144, p. 273-288.

GRAHAM, J.; AMOS, B. \& PLUMPTRE, T. (editors). Principles for Good Governance in the 21st Century. Otawa: Institute on Governance, Policy Brief $N^{0} 15,2003$. Disponible en Internet: http://iog.ca/sites/iog/files/policybrief15_0.pdf

HALL, C.M. Tourism and transition: governance, transformation and development. WaIlingford, Oxfordshire: CABI Publishing, 2004.

HALL, C.M. Tourism, governance and the (mis-)location of power. Tourism, power and space. Londres: Routledge, 2007, p. 247-269. 
HAMNETT, C. The Madness of Mortgage Lenders Housing finance and the financial Crisis. Londres: King's College, 2009.

HAYS, J.C. \& LONGINO, C.F. Florida migration in the AHEAD study, 1993-1995: A note on the flight of the oldest retirees. Research on Aging, 2002, № 24, p. 473-483.

HENDERSON, A. Why Regions Matter: Sub-state Polities in Comparative perspective, Regional and Federal Studies, 2010, Vol. 20, $N^{\circ} 4-5$, p. 439-445.

HOF, A. \& BLÁZQUEZ-SALOM, M. The Linkages between Real Estate Tourism and Urban Sprawl in Majorca (Balearic Islands, Spain). Land 2, 2013, № 2, p. 252-277.

IOANNIDES, D. \& DEBBAGE, K. Neofordism and flexible specialization in the travel industry. In: IOANNIDES, D. \& DEBBAGE, K. (editors). The economic geography of the tourist industry. Londres: Routledge, 1998, p. 99-122.

JANOSCHKA, M. Nuevas geografías migratorias en América Latina: prácticas de ciudadanía en un destino de turismo residencial. Scripta Nova. Revista Electrónica de Geografía y Ciencias Sociales, 2013, Vol. XVII, No 439. Disponible en Internet: http://www.ub.es/geocrit/sn/sn-439.htm

LIPIETZ, B. \& PIETERSE, E. Report on eDialogue 5: Governance \& Participation 16 November-08 December 2009. In: World Urban Forum 5, Rio de Janeiro 22-26 March, 2010. Disponible en Internet: http://www. unhabitat.org/downloads/docs/Dialogue5.pdf

LÓPEZ, D; ANTON, S.; NAVARRO, E.; PERELLI, O. y SASTRE, F. Cambios y transformaciones en el actual modelo turístico de España. Annals of Tourism Research en Español, 2005, Vol. 7, № 2, p. 423-446.

MARTÍNEZ, M. y ROSENDE, S. Participación ciudadana en las agendas 21 locales: cuestiones críticas de la gobernanza urbana. Scripta Nova. Revista Electrónica de Geografía y Ciencias Sociales, 2011, Vol. XV, № 355. Disponible en Internet: http://www. ub.es/geocrit/sn/sn-355.htm
MASSON-VINCENT, M. Governance and geography explaining the importance of regional planning to citizens, stakeholders in their living space. Boletín de la Asociación de Geógrafos Españoles, 2008, № 46, p. 77-95.

MASSON-VINCENT, M.; DUBUS, N.; BLEY, D.; VOIRON-CANICIO, C.; HELLE, C.; CHEYLAN, J.P.; DOUART, P.; DOUGUEDROIT, A.; FERRIER, J.P.; JACOB, F.; LAMPIN, C.; MAIGNANT, G. \& PIOT, J.Y. La Géogouvernance: un concept novateur?. Cybergeo: European Journal of Geography. Aménagement, Urbanisme, document, 2012, Nº 587. Disponible en Internet: http://cybergeo. revues.org/25086

MAYNTZ, R. Nuevos desafíos de la teoría de Governance. Instituciones y Desarrollo, 2000, N ${ }^{\circ} 7$, p. 35-51.

MURRAY, I. Geografies del capitalisme balear: poder, metabolisme socioeconòmic i petjada ecològica d'una superpotència turística. Palma: Tesis doctoral, Universitat de les Illes Balears, 2012. Disponible en Internet: http:// www.tdx.cat/handle/10803/104203

MURRAY, I.; RULLÁN, O. y BLÁZQUEZ, M. Las huellas territoriales de deterioro ecológico. El trasfondo oculto de la explosión turística en Baleares. Scripta Nova: Revista Electrónica de Geografía y Ciencias Sociales, 2005, Vol. 9, № 199. Disponible en Internet: http://www.ub.es/geocrit/sn/sn-199.htm.

NAREDO, J.M. y MONTIEL, A. EI modelo inmobiliario español y su culminación en el caso valenciano. Barcelona: Icaria, 2011.

NAVARRO, E. ¿Puede seguir creciendo la Costa del Sol?: indicadores de saturación de un destino turístico. Málaga: Diputación Provincial de Málaga, 2003.

OBSERVATORIO DE LA SOSTENIBILIDAD EN ESPAÑA. Cambios de ocupación del suelo en España. 2006. Disponible en Internet: http://www.sostenibilidad-es.org/es/informes/ informes-tematicos

PALAN, R.; MURPHY, R. y CHAVAGNEUX, C. Tax Havens: How Globalization Really Works. Nueva York: Cornell University Press, 2010. 

DE FUERTE PRESIÓN INMOBILIARIA. ANÁLISIS DE BUENAS PRÁCTICAS LOCALES EN LA COSTA DE CÁDIZ (ESPAÑA)

PAQUET, G. Gouvernance, mode d'emploi. Montréal: Liber Eds., 2009.

PASCUAL, J.M. y GODAS, X. (coordinadores). El buen gobierno 2.0. La gobernanza democrática territorial. Valencia: Tirant lo Blanch, 2010.

PATTERSON, I. Growing Older: Tourism and Leisure Behaviour of Older Adults. Wallingford, Oxfordshire: CABI Publishing, 2006.

PIERRE, J. (editor). Governance. Oxford: Oxford University Press, 1999.

PIERRE, J. Understanding Governance. In: PIERRE, J. (editor). Debating Governance. Oxford: Oxford University Press, 2000, p. 1-10.

ROMERO, J. y FARINÓS, J. (editors). Gobernanza territorial en España. Claroscuros de un proceso a partir del estudio de casos. Valencia: Publicacions de la Universitat de València, Colección Desarrollo Territorial, 2006.

ROMERO, J. y FARINÓS, J. Redescubriendo la gobernanza más allá del buen gobierno. Democracia como base, desarrollo territorial como resultado. Boletín de la Asociación de Geógrafos Españoles, 2011, № 56, p. 295319.

RULLÁN, O. Una técnica urbanística para contener el crecimiento residencial en espacios con fuerte presión inmobiliaria. Scripta Nova. Revista electrónica de Geografía y Ciencias Sociales, 2005, Vol. 194, Nº 32. Disponible en Internet: http://www.ub.es./ geocrit/sn/sn-194-9.htm

RULLÁN, O. La regulación del crecimiento urbanístico en el litoral mediterráneo español. Ciudad y Territorio. Estudios Territoriales, 2011, Vol. XLIII, No 168, p. 279-297.

RULLÁN, O. Urbanismo expansivo en el Estado español: de la utopía a la realidad. In: GOZÁLVEZ, V. y MARCO, J.A. (coordinadores) Geografía: retos ambientales y territoriales: conferencias, ponencias, relatorías, mesas redondas. Alicante: Universidad de Alicante, 2012, p. 165-211.
SHAW, G. \& WILLIAMS, A.M. Tourism and tourism spaces. Londres: SAGE, 2004.

SORENSEN, E. \& TORFING, J. Making Governance networks effective and democratic through metagovernance. Public Administration, 2009, Vol. 87, № 2, p. 234-58.

STEVENSON, S. y YOUNG, J. Comportamiento especulativo en los mercados de la vivienda: Una perspectiva internacional. Papeles de Economía Española, 2006, № 109, p. 14-26.

SWYNGEDOUW, E. Governance innovation and the citizen: the janus face of Governance-beyond-the-state. Urban Studies, 2005, Vol. 42, No 11, p. 1991-2006.

VERA, J.F. \& RODRÍGUEZ, I. Tourism strategies for the renovation of mature coastal destinations in Spain. Sustainable Tourism IV. Southampton: WITT Press, 2010.

VERA, J.F.; LÓPEZ PALOMEQUE, F.; MARCHENA, M. y ANTÓN, S. (coordinadores). Análisis territorial del turismo y planificación de destinos turísticos. Valencia: Ed. Tirant Io Blanch, 2011.

VERA, J.F. y RODRÍGUEZ, I. (coordinadores). Renovación y reestructuración de destinos turísticos en áreas costeras: marco de análisis, procesos, instrumentos y realidades. Valencia: Universitat de València, 2012.

VILLAR, A. Territorio, turismo y paisaje: El proceso de urbanización en el litoral de Andalucía. El papel de los campos de golf. Sevilla: Junta de Andalucía, 2012.

VILLAR, A. y FERNÁNDEZ-TABALES, A. Diagnóstico y perspectiva territorial del golf en Andalucía: entre la cualificación turística y el desarrollismo inmobiliario. Boletín de la Asociación de Geógrafos Españoles, 2013, № 62, p. 357-378.

VIVES, S. Producing a successful city. Neoliberal urbanism and gentrification in the tourist city. The case of Palma (Majorca). Urban Studies Research, 2011. Disponible en Internet: http://www.hindawi.com/journals/ usr/2011/989676/ref/ 
WALTERS, W.H. Later-Life Migration in the United States: A Review of Recent Research. Journal of Planning Literature, 2002, Vol. 17, $\mathrm{N}^{\circ} 1$, p. 37-66.

WARNES, A.M. \& WILLIAMS, A. Older Migrants in Europe: A New Focus for Migration Studies. Journal of Ethnic and Migration Studies, 2006, Vol. 32, № 8, p. 1257-1281.
WILLIAMS, A. \& HALL, M. Tourism and migration: new relationships between production and consumption. Tourism Geographies, 2000, Vol. 2, № 1, p. 5-27. 